\title{
Increase in Percentage of Seronegative Toxoplasma gondii and Cytomegalovirus in Pregnant Women: An Improvement in Hygienic Conditions in Certain Areas?
}

\author{
Dan-Bogdan Navolan ${ }^{1, *}$, Florin Gorun ${ }^{1}$, Cristian Oancea ${ }^{2}$, Ioana-Mihaela Ciohat ${ }^{3}$, \\ Daniel Malița ${ }^{4}$ and Marius Lucian Craina ${ }^{1}$ \\ ${ }^{\text {I }}$ Department of Obstetrics and Gynecology, Victor Babes University of Medicine and Pharmacy, 30004I Timișoara, \\ Romania; florin.gorun@yahoo.com (F.G.); mariuscraina@hotmail.com (M.L.C.) \\ ${ }^{2}$ Department of Infectious Diseases, Victor Babes University of Medicine and Pharmacy, 30004I Timișoara, \\ Romania; oancea@umft.ro \\ ${ }^{3}$ Laboratory of Antenatal Medicine, City Emergency Hospital, 30004I Timișoara, Romania; tucaioana@yahoo.com \\ ${ }^{4}$ Department of Radiology, Victor Babes University of Medicine and Pharmacy, 30004I Timişoara, Romania; \\ dmalita@gmail.com \\ *Correspondence: navolan@yahoo.com; Tel.: +40-722-960-9II
}

Received: 28 September 2020; Accepted: 22 October 2020; Published: 17 November 2020

\begin{abstract}
I) Background: Toxoplasma gondii and cytomegalovirus belong to a group of pathogens entities called TORCH agents. TORCH represents an acronym which derives from the name of a series of certain pathogenic agents (Toxoplasma gondii, Other agents, Rubella virus, Cytomegalovirus, Herpes virus). They could cross the placenta barrier and cause serious damage to the fetus if a primary infection occurs in a pregnant woman. Immunized women are relatively protected against a reinfection and the risk of a materno-fetal infection in these categories of pregnant women is considered low. (2) Aim of the study: To analyze changes in the percentage of pregnant women seronegative to Toxoplasma gondii and cytomegalovirus along a period of ten years, from 2008 to 2018. (3) Material and Methods: We studied the changes in percentage of seronegative Toxoplasma gondii and Cytomegalovirus pregnant women along two periods: 2008-2010 and 2015-2018. Only pregnant women with declared medium of provenience and unequivocal results were enrolled in the study. (4) Results: In urban areas, we found an increase in the percentage of pregnant women seronegative to Toxoplasma gondii $(\mathrm{RR}=\mathrm{I} .488, p<\mathrm{0.000I})$, respectively to cytomegalovirus $(\mathrm{RR}=\mathrm{I.985}, p<0.000 \mathrm{I})$, from 2008-2010 to 2015-2018. A similar increasing trend was found also in rural areas: Toxoplasma gondii $(\mathrm{RR}=1.136, p<0.0322)$, respectively cytomegalovirus $(\mathrm{RR}=\mathrm{I} .088, p<0.8265)$ but it did not reach a significant threshold for cytomegalovirus. (5) Conclusion: Our study showed that the percentage of women seronegative to Toxoplasma gondii and cytomegalovirus antibodies increases along a period of ten years, from 2008-2010 to 2015-2018, in both urban and rural areas. Probably, the main cause of this trend is represented by the improvement in hygienic condition and food quality control. These results present an argument for continuing the TORCH screening of pregnant women.
\end{abstract}

Keywords: Toxoplasma gondii; cytomegalovirus; trend; susceptibility; pregnant women

How to cite: Navolan, D.-B.; Gorun, F.; Oancea, C.; Ciohat, I.-M.; Malița, D.; Craina, M.L. Increase in Percentage of Seronegative Toxoplasma gondii and Cytomegalovirus in Pregnant Women: An Improvement in Hygienic Conditions in Certain Areas?. Timisoara Med. 2020, 2020(I), 9; doi:I0.35995/tmj202001009. 


\section{Introduction}

Toxoplasma gondii and cytomegalovirus belong to a group of pathogens entities called TORCH agents. TORCH represents an acronym which derives from the name of a series of certain pathogenic agents (Toxoplasma gondii, Other agents, Rubella virus, Cytomegalovirus, Herpes virus). They could cross the placenta barrier and cause serious damage to the fetus if a primary infection occurs during a woman's pregnancy [I]. Immunized women are relatively protected against a reinfection and the risk of a materno-fetal infection in these categories of pregnant women is considered to be low $[2,3]$. In particular cases, certain IgG seropositive women could be reinfected if they contact other strains of the same pathogenous agents or when the immune system is weakened by an immunosuppressive therapy or disease [4,5]. Most immunized women have a sufficiently high IgG antibodies titer to neutralize agents before they cross the placenta and to prevent infection and damage in the fetus $[2,3]$.

Toxoplasma gondii is an intracellular parasite and an important cause of congenital malformations in many countries [6]. The main hosts where the reproduction of Toxoplasma gondii takes place are domestic and wild cats [7], but other species could be infected and carry oocysts, as well $[8,9]$. In adult people, infection occurs upon contact with or ingestion of sporulated oocysts from soil, water or undercooked meat [7]. Most infected pregnant women are asymptomatic or show only mild symptoms, such as fever, headache, swollen lymph glands, general asthenia, pain and inflammation [3,IO]. Often primary infections in pregnant women go unobserved and could be evoked only later by anamnesis, when signs of fetal damage appear. Intrauterine infection in early stages of pregnancy is often a cause of spontaneous abortion, and in later stages a cause of different congenital malformations such as retinochoroiditis, intracranial calcifications, hydrocephalus, hepatosplenomegaly, microcephaly or intrauterine growth restriction (IUGR) [Io]. Diagnosis of acute toxoplasmosis needs serological and sometimes molecular biological testing of samples (amniotic fluid or fetal blood) [Io].

Cytomegalovirus is part of the Herpesviridae family, and, after a primary disease, it causes a persistent and latent infection of the host $[2,5]$. Usually, an IgG anti cytomegalovirus seropositive women is immune to reinfection but sometimes, if the immune system is weakened (immunosuppressive diseases (HIV, etc.) or immunosuppressive treatment (steroids, chemotherapy, etc.)), a reactivation may appear [5]. Often, a primary infection is asymptomatic or causes only a few symptoms [II].

Congenital cytomegalovirus infection causes microcephaly, hepatosplenomegaly, IUGR and neuro-sensorial deficits: chorioretinitis, optic atrophy and deafness [12]. Although infected neonates are often asymptomatic, they could develop lifelong sequelae [I2].

Studies showed that pregnant women who are IgG seropositive to Toxoplasma gondii and cytomegalovirus are at a low risk of infecting the fetus, while seronegative ones need prophylactic hygienic measures to prevent a primary infection during pregnancy. To find out which women are seronegative, public health authorities offer in certain countries serological screening programs against these agents $[\mathrm{I}-3]$. Faced with public health costs on the one hand and the desire to reduce the prevalence of congenital infections on the other hand, public health authorities need to evaluate the cost efficiency of screening programs. Such an analysis needs real seroprevalence data, such as the results of our study.

The aim of our study was to analyze the changes in percentage of pregnant women seronegative to Toxoplasma gondii and cytomegalovirus along a period of ten years from 2008 to 2018. 


\section{Materials and Methods}

\section{Study Population}

We studied the changes in percentage of seronegative Toxoplasma gondii and Cytomegalovirus pregnant women along two periods: 2008-20I0 and 20I5-20I8 (Table I). Only pregnant women with declared medium of provenience and unequivocal results were enrolled in the study.

Table 1. Pregnant women tested against IgG anti-Toxoplasma gondii and Cytomegalovirus according the medium of provenience.

\begin{tabular}{lllll}
\hline & $\mathbf{2 0 0 8 - 2 0 1 0}$ & & $\mathbf{2 0 1 5 - 2 0 1 8}$ & \\
\hline \multirow{2}{*}{ Toxoplasma gondii } & $\mathrm{I} 457$ & & 5432 & \\
& $\mathrm{U}=\mathrm{I0} 5 \mathrm{I}$ & $\mathrm{R}=406$ & $\mathrm{U}=354 \mathrm{I}$ & $\mathrm{R}=\mathrm{I} 89 \mathrm{I}$ \\
Cytomegalovirus & $\mathrm{I} 46 \mathrm{I}$ & & 5500 & \\
& $\mathrm{U}=\mathrm{I} 054$ & $\mathrm{R}=407$ & $\mathrm{U}=3570$ & $\mathrm{R}=1930$ \\
\hline
\end{tabular}

\section{Measurement of IgG Antibodies against Toxoplasma gondii and Cytomegalovirus}

Measurement of IgG anti-Toxoplasma gondii and IgG-anti-Cytomeglovirus antibodies titer was performed by immune-chemiluminescence using an Immulite One Machine (2008-2010) and Immulite 2000 Machine (Diagnostic Products Corporation) (2015-2018), respectively, and commercial tests (Siemens Healthcare Diagnostics Products). Patients were grouped as seropositive and seronegative, according to cut-off values recommended by the manufacturer.

Statistical methods. Astraia database and Microsoft Office Excel were used to store data. Instat GraphPad Prism 8.o.2 software was used for statistical evaluation. To assess the significance of the differences between groups, Fisher's exact test (proportions) was used.

Ethical issues. The present study was approved by the Institutional Board of the 'Victor Babes' University of Medicine and Pharmacy (Timisoara, Romania) (approval no. 848/o6.04.20II). The study meets the ethical guidelines, including adherence to the legal requirements of the study country.

\section{Results}

Increase in Percentage of Seronegative IgG-Anti-Toxoplasma gondii and Cytomegalovirus Pregnant Women from 2008-2010 to 2015-2018

Our results showed an increase in percentage of pregnant women seronegative to Toxoplasma gondii $(\mathrm{RR}=\mathrm{I} .077, p=0.003 \mathrm{I})$, respectively, cytomegalovirus $(\mathrm{RR}=\mathrm{I} .783, p \leq 0.000 \mathrm{I})$ (Table 2$).$

Trends in Percentage of Pregnant Women Seronegative to Toxoplasma gondii and Cytomegalovirus from 2008-2010 to 2015-2018 Accorrding the Place of Residence

In urban areas we found an increase in pregnant women seronegative to Toxoplasma gondii ( $\mathrm{RR}=\mathrm{I} .488$, $p<0.000 \mathrm{I}$ ), respectively, cytomegalovirus ( $\mathrm{RR}=\mathrm{I} .985, p<0.000 \mathrm{I}$ ) (Table 2 ). A similar increasing trend was also found in rural areas: Toxoplasma gondii $(\mathrm{RR}=\mathrm{I.13} 6, p<0.0322)$, respectively, cytomegalovirus $(\mathrm{RR}=\mathrm{I.088,} p<0.8265)$, but did not reach a significant threshold for cytomegalovirus. 
Table 2. Seronegative pregnant women to Toxoplasma gondii and cytomegalovirus according to place of residence along two periods: 2008-2010 and 2015-2018.

\begin{tabular}{|c|c|c|c|c|}
\hline & $2008-2010$ & $2015-2018$ & RR & $p$ Value \\
\hline \multicolumn{5}{|l|}{ All } \\
\hline Toxoplasma gondii & $819 / 1457$ (56.21\%) & $3324 / 5432$ (6I.19\%) & I.077 & $0.003 \mathrm{I}$ \\
\hline CMV & $77 / \mathrm{I} 46 \mathrm{I}(5.27 \%)$ & $498 / 5500(9.05 \%)$ & 1.783 & $<0.0001$ \\
\hline \multicolumn{5}{|l|}{ Urban areas } \\
\hline Toxoplasma gondii & $638 / 1457(43.78 \%)$ & $2307 / 354 \mathrm{I}(65.15 \%)$ & I. 488 & $<0.0001$ \\
\hline CMV & $58 / 1054(5.50 \%)$ & $390 / 3570$ (10.92\%) & 1.985 & $<0.0001$ \\
\hline \multicolumn{5}{|l|}{ Rural areas } \\
\hline Toxoplasma gondii & $194 / 406(47.78 \%)$ & IOI7/I89I (53.78\%) & I.136 & $=0.0322$ \\
\hline CMV & $19 / 407(4.66 \%)$ & $98 / 1930(5.07 \%)$ & I.088 & 0.8265 \\
\hline
\end{tabular}

\section{Discussion}

Our results are part of the largest study carried out in our country. Since our previous reports presented changes in seroprevalence against TORCH agents in pregnant women along a period of ten years, our present research analyzes the trend of percentage of pregnant women seronegative to cytomegalovirus and Toxoplasma gondii in the same period (2008-2018). Herein, we also discuss some possible explanations for this upward trend and compare our data with other data from the literature.

Romania fits into the group of countries with pregnant women with low susceptibility to cytomegalovirus and medium susceptibility to Toxoplasma gondii. Usually, the higher the percentage of seropositive persons in a population, the lower the risk of a primary infection.

Seroprevalence studies showed that in economically developed countries (western European Union Countries), a higher percent $(30-60 \%)$ of people are seronegative to cytomegalovirus compared to low-income countries (only o-4\% in Africa and East Asia) [13]. Studies performed in Africa showed low rates of seronegativity to cytomegalovirus of approximatively o\% in Nigeria [I4], 2.8\% in Benin [I5] and $4 \%$ in Egypt [16]. Interesting studies performed in the same country among socio-economically different groups of people showed that people with higher education and income had a higher seronegative rate compared to people with lower socio-economic status [17].

Analyzing the course of seronegativity to CMV over the years in Japan showed that the prevalence of seronegative people increased over time, from $30.1 \%$ in 2003 to $34.8 \%$ in 2012 [18]. Scientists from Japan speculate that the decline in birth rate reduces the chance of child-to-child contact and could explain the increase in prevalence of seronegative people. Another cause could be better hygiene counseling of pregnant women by public authorities and spread of information about the consequences of congenital CMV infection [18].

Our study shows that the percentage of seronegative pregnant women increased overall in our region, from $5.27 \%$ to $9.05 \%$. Such a trend was found in urban areas, with an increase from $5.5 \%$ to 10.92\%. A similar ascending trend from $4.66 \%$ to $5.07 \%$ was found in rural areas, too but it did not reach a significant threshold. We have no explanation as to why this trend was not significant among pregnant women from rural areas. Maybe the smaller number of women in the rural group did not ensure a sufficient number of patients producing significant results. Another explanation could be that the hygienic improvement or the decline in birth rates was not significant in rural areas in this interval. 
Toxoplasma gond $i i$ is a worldwide spread parasite. The percentage of general population who are seronegative to Toxoplasma gondii varies between 70 and $75 \%$ around the globe [7], while it drops to $28 \%$ in Latin America [19]. In other European countries, the percentage of seronegative childbearing women varies from $81 \%$ in Great Britain [20] to $56 \%$ in France [2I].

Our data showed that the percentage of seronegative pregnant women increased overall from $56.21 \%$ (2008-2010) to 61.19\% (2015-2018). The same trend was found in both urban (from $43.78 \%$ to $65.15 \%$ ) and rural (from $47.78 \%$ to $53.78 \%$ ) areas.

An increase in the percentage of seronegative Toxoplasma gondii persons was found in other countries, too. For example, in the United States of America, this percentage increased from 77-86\% (1988-1994) to 91\% (1999-2004) and 94\% (2009-2010). The increase in percentage of seronegative pregnant women was steeper in urban areas than in rural areas, maybe because of better improvement in hygienic conditions in urban areas. Similar to cytomegalovirus infection, low socio-economic status, contact with animals and uncooked meat are associated with a higher contamination rate and a lower seronegativity rate [22,23].

Such an increasing trend in the percentage of seronegative pregnant women leads to more attention from public authorities and the development of more extensive serological screening programs. More information strategies about preventive measures and about the risk of congenital infection after primary contact with these agents must be delivered to the population.

There are certain differences between the urban and rural population in terms of hygiene. For instance, studies showed that some infectious agents are present in backyard pigs in Romania and the consumption of pork meat at home may increase the risk of human infection [24]. Water supply and hygienic features are different $[25]$. This may explain some of the differences between rural and urban areas.

\section{Conclusions}

Our study showed that the percentage of women seronegative to Toxoplasma gondii and cytomegalovirus antibodies increases along a period of ten years, from 2008-2010 to 2015-2018, in both urban and rural areas. Probably, the main cause of this trend is represented by the improvement in hygienic condition and food quality control. These results argue for continuing the TORCH screening of pregnant women.

Author Contributions: D.-B.N., F.G., I.-M.C., and M.L.C. were involved in the conception of the study and data interpretation. C.O. and D.M. contributed to data collection and performed the statistical analysis. I.-M.C. performed serological testing. D.-B.N., F.G., I.-M.C., and M.L.C. wrote the manuscript. I.-M.C., C.O. and D.M. revised the manuscript for important intellectual content. All authors read and approved the final version of the manuscript.

Funding: This research received no external funding.

Conflicts of Interest: The authors declare no conflict of interest.

\section{References}

I. Navolan, D.; Ciohat, I.; Tigla, A.; Vasies, D.; Dumitrascu, D. Risk Assessment for TORCH complex infection agents during pregnancy: Preliminary study. TMJ 2012, 62, 15-19.

2. Gorun, F.; Motoi, S.; Malita, D.; Navolan, D.; Nemescu, D.; Olariu, T.; Craina, M.; Vilibic-Cavlek, T.; Ciohat, I.; Boda, D.; et al. Cytomegalovirus seroprevalence in pregnant women in the western region of Romania: A large-scale study. ETM 2020, 20, 2439-2443. [CrossRef] [PubMed] 
3. Motoi, S.; Navolan, D.; Malita, D.; Ciohat, I.; Nemescu, D.; Manciuc, C.; Gorun, F.; Vilibic-Cavlek, T.; Boda, D.; Craina, M.; et al. A decreasing trend in Toxoplasma gondii seroprevalence among pregnant women in Romania-Results of a large scale study. ETM 2020, 20, 3536-3540.

4. Pomares, C.; Devillard, S.; Holmes, T.H.; Olariu, T.R.; Press, C.J.; Ramirez, R.; Talucod, J.; Estran, R.; Su, C.; Dubey, J.P.; et al. Genetic Characterization of Toxoplasma gondii DNA Samples Isolated From Humans Living in North America: An Unexpected High Prevalence of Atypical Genotypes. J. Infect. Dis. 2018, 218, 1783-179I. [CrossRef] [PubMed]

5. Harrison, T.; Kasper, D.; Hauser, S.; Jameson, J.; Fauci, A.; Longo, D.; Loscalzo, J. Harrison's Principles of Internal Medicine, 2oth ed.; Publisher McGraw-Hill Education: New York, NY, USA, 2018; pp. 136I-I365.

6. Iemmi, T.; Vismarra, A.; Mangia, C.; Zanin, R.; Genchi, M.; Lanfranchi, P.; Kramer, L.H.; Formenti, N.; Ferrari, N. Toxoplasma gondii in the Eurasian kestrel (Falco tinnunculus) in northern Italy. Parasites Vectors 2020, 13, 262. [CrossRef] [PubMed]

7. English, E.D.; Striepen, B. The cat is out of the bag: How parasites know their hosts. PLoS Biol. 2019, 17, e30oo446. [CrossRef] [PubMed]

8. Duong, H.D.; Appiah-Kwarteng, C.; Takashima, Y.; Aye, K.M.; Nagayasu, E.; Yoshida, A. A novel luciferase-linked antibody capture assay (LACA) for the diagnosis of Toxoplasma gondii infection in chickens. Parasitol. Int. 2020, 77, I02125. [CrossRef]

9. Foroutan, M.; Fakhri, Y.; Riahi, S.M.; Ebrahimpour, S.; Namroodi, S.; Taghipour, A.; Spotin, A.; Gamble, H.R.; Rostami, A. The global seroprevalence of Toxoplasma gondii in pigs: A systematic review and meta-analysis. Vet. Parasitol. 2019, 269, 42-52. [CrossRef]

Io. Khan, K.; Khan, W. Congenital toxoplasmosis: An overview of the neurological and ocular manifestations. Parasitol. Int. 2018, 67, 715-721. [CrossRef]

II. Périllaud-Dubois, C.; Bouthry, E.; Jadoui, A.; Leng, A.L.; Roque-Afonso, A.M.; Vauloup-Fellous, C. Positive predictive values of CMV-IgM and importance of CMV-IgG avidity testing in detecting primary infection in three different clinical settings. A French retrospective cohort study. J. Clin. Virol. 2020, 9, I0464I. [CrossRef]

I2. Kagan, K.; Hamprecht, K. Cytomegalovirus infection in pregnancy. Arch. Gynecol. Obstet. 2017, 296, I5-26. [CrossRef]

13. Al Mana, H.; Yassine, H.M.; Younes, N.N.; Al-Mohannadi, A.; Al-Sadeq, D.W.; Alhababi, D.; Nasser, E.A.; Nasrallah, G.K. The Current Status of Cytomegalovirus (CMV) Prevalence in the MENA Region: A Systematic Review. Pathogens 2019, 8, 213. [CrossRef]

I4. Williams, J.O.; Fagbami, A.H.; Omilabu, S.A. Cytomegalovirus antibodies in Nigeria. Trans. R. Soc. Trop. Med. Hyg. 1989, 83, 260-3io. [CrossRef]

I5. Rodier, M.H.; Berthonneau, J.; Bourgoin, A.; Giraudeau, G.; Agius, G.; Burucoa, C.; Hekpazo, A.; Jacquemin, J.L. Seroprevalences of Toxoplasma, malaria, rubella, cytomegalovirus, HIV and treponemal infections among pregnant women in Cotonou, Republic of Benin. Acta Trop. 1995, 59, 27I-277. [CrossRef]

I6. El-Nawawy, A.; Soliman, A.T.; El Azzouni, O.; Amer, E.-S.; Karim, M.A.; Demian, S.; El-Sayed, M. Maternal and neonatal prevalence of toxoplasma and cytomegalovirus (CMV) antibodies and hepatitis-B antigens in an Egyptian rural area.J. Trop. Pediatr. 1996, 42, 154-157. [CrossRef]

17. Odland, M.L.; Strand, K.M.; Nordbø, S.A.; Forsmo, S.; Austgulen, R.; Iversen, A.C. Changing patterns of cytomegalovirus seroprevalence among pregnant women in Norway between 1995 and 2009 examined in the Norwegian Mother and Child Cohort Study and two cohorts from Sør-Trøndelag County: A cross-sectional study. BMJ Open 2013, 3, eoozo66. [CrossRef]

I8. Taniguchi, K.; Watanabe, N.; Sato, A.; Jwa, S.C.; Suzuki, T.; Yamanobe, Y.; Sago, H.; Kozuka, K. Changes in cytomegalovirus seroprevalence in pregnant Japanese women-A ro-year single center study. J. Clin. Virol. 2014, 59, 192-194. [CrossRef]

19. Rorman, E.; Zamir, C.S.; Rilkis, I.; Ben-David, H. Congenital toxoplasmosis-prenatal aspects of Toxoplasma gondii infection. Reprod. Toxicol. 2006, 21, 458-472. [CrossRef]

20. Nash, J.Q.; Chissel, S.; Jones, J.; Warburton, F.; Verlander, N.Q. Risk factors for toxoplasmosis in pregnant women in Kent, United Kingdom. Epidemiol. Infect. 2005, 133, 475-483. [CrossRef]

2I. Berger, F.; Goulet, V.; Le Strat, Y.; Desenclos, J.C. Toxoplasmosis among pregnant women in France: Risk factors and change of prevalence between 1995 and 2003. Rev. Epidemiol. Sante Publique 2009, 57, 241-248. [CrossRef]

22. Belluco, S.; Mancin, M.; Conficoni, D.; Simonato, G.; Pietrobelli, M.; Ricci, A. Investigating the Determinants of Toxoplasma gondii Prevalence in Meat: A Systematic Review and Meta-Regression. PLoS ONE 2016, 11, eors3856. [CrossRef] [PubMed]

23. Mareze, M.; Benitez, A.D.N.; Brandão, A.P.D.; Pinto-Ferreira, F.; Miura, A.C.; Martins, F.D.C.; Caldart, E.T.; Biondo, A.W.; Freire, R.L.; Mitsuka-Breganó, R.; et al. Socioeconomic vulnerability associated to Toxoplasma gondii exposure in southern Brazil. PLoS ONE 2019, 14, e0212375. [CrossRef] [PubMed] 
24. Paştiu, A.I.; Cozma-Petruţ, A.; Mercier, A.; Balea, A.; Galal, L.; Mircean, V.; Pusta, D.L.; Bogdan, L.; Györke, A. Prevalence and genetic characterization of Toxoplasma gondii in naturally infected backyard pigs intended for familial consumption in Romania. Parasites Vectors 2019, 12, 586. [CrossRef] [PubMed]

25. Frone, S.; Frone, D.F. Promoting access to water supply and sanitation: Issues and challenges in Romania. Econ. Eng. Agric. Rural Dev. 2013, 13, 165-170.

(C) 2020 Copyright by the authors. Licensed as an open access article using a CC BY 4.0 license. 